\title{
ON NONCONFIGURATIONAL STRUCTURES *
}

KEN HALE

\author{
Massachusetts Institute of Technology
}

At last since the publication of Chomsky's Lectures on Government and Binding (1981), it has been customary to acknowledge the existence of a typological distinction between «configurational» and "nonconfigurational» languages. A number of writers have since attempted to determine precisely what this distinction is (e.g., Whitman, 1982; Hale, 1983; Jelinek, 1984; Mohanan, 1983/4; Saito, 1985). In Hale (1983), following Chomsky (1981: 127-135), or rather, following my interpretation of that discussion, I defined the Configurationality Parameter in terms of the Projection Principle (Chomsky, 1981: 38, and elsewhere) I will refer to this as the NLLT formulation of the parameter. According to that formulation, the Projection Principle holds universally of the LS (lexical structure) representation, but languages differ according to whether or not it holds of PS (phonologically overt phrase structure) - in configurational languages it does, in nonconfigurational languages it does not (see Mohanan, 1983/4, for a virtually identical interpretation of Chomsky's original discussion). The intention there was to account for various observable properties of certain putative nonconfigurational languages, such as the great freedom of surface word order (a PS phenomenon) and extensive use of «null anaphora» (i.e., arguments not overtly present at PS) in Warlpiri of Central Australia.

I think this idea is basically correct, but certain conceptual improvements are now possible, arising in large part from the work of linguists such as Jelinek (1984) and Saito (1985), who have been justifiably critical of the NLLT formulation, and from

* I wish to express my gratitude to the Harvard Workshop on Korean Linguistics for allowing me to present these ideas before it, despite the fact that my paper deals with a language other than Korean. I am especially indebted to Hynon-Sook Choe for stimulating discussions on various aspects of Korean, including the issue of Korean configurationality. 
serious consideration of the concern engendered by the NLLT formulation to the effect that it «made languages seem more different than ought to be possible» in that it had them differing in relation to the Projection Principle, a fundamental aspect of the grammars of all languages.

In the present paper, I will attempt to show as precisely as possible the manner in which the PS representation of sentences in so-called nonconfigurational languages is related to the LS representation and, in the process, the exact sense in which the Projection Principle can fail to hold at (or more accurately, be irrelevant to) the PS representation. The latter aspect of the theory of configurationality will not introduce relations which are in any way new or unique to nonconfigurational languages. In fact, I will argue that nonconfigurationality is not a global property of languages; rather, it is a property of constructions. If this is so, then it will probably be possible, ultimately, to demonstrate both that established "configurational» languages, such as English, possess nonconfigurational constructions and that putative "nonconfigurational» languages, such as Navajo, possess configurational constructions.

In the course of the ensuing discussion, it should become evident that the term "configurationality» is not a particularly appropriate one, since the notion "configuration", in the sense of a hierarchical organization of constituents is essential to all languages (certainly at the LS representation, but arguably also at PS). Moreover, the "parameter» involved here has nothing to do directly with configurational structure per se but rather with the relation between the LS and PS aspects of the syntactic projections of verbs. Having no terminological improvement to suggest, however, I will continue to talk in terms of «configurationality» and in terms of "(non)configurational constructions».

It has been an expository mistake, largely my own, to tie the configurationality question too closely to the phenomenon of free word order. The latter property is not criterial for nonconfigurationality, and it never has been. For this reason, I will use examples from Navajo, a language with relatively fixed word order which I have long assumed to be nonconfigurational, to illustrate what I think the essential property of nonconfigurational constructions is. Prior to this, however, I will attempt to articulate a view of the syntatic projection of lexical categories as involving two conceptually distinguishable representations - (1) LS, the "grammatical projection», which defines, for example, the organization of the arguments of a verb in relation to the latter, thereby identifying the grammatical functions (GFs) borne by the 
verb's arguments; and (2) PS, the "phonological projection», defining the structural relations among the phonologically overt words making up phrases and sentences. This will require some preliminary discussion of the structure of lexical items and their relation to syntactic structures. I will begin the discussion with some elementary examples from English, using the transitive verb cut, exemplified in the following sentences:

(1) John cut the bread.

(2) I saw John cut the bread.

(3) The bread cuts easily.

I take the position that the lexical entry of a verb contains, in addition to a registration of its morphophonological properties, two fundamental parts relevant to grammar: a Lexical Conceptual Structure (LCS; roughly, its «meaning»), and a syntactic projection (its LS and PS representations). The LCS of a verb is a representation of the concept (action, process, or state) which the verb denotes. In the case of English cut, I tentatively propose that the LCS is as in (4) below (formulated in English prose), in which the variables $x$ and $y$ correspond to the participants in the action denoted:

(4) [ $\mathrm{x}$ produces a linear separation in the material integrity of $y$, by sharp edge coming into contact with the latter].

The syntactic projection of a lexical item is defined by X-bar theory. Since the verb in English is autonomous from the category Infl, only the verb's «internal» argument(s), if any, will be represented in the syntactic projection at the lexical representation. This follows, because the maximal projection of the lexical category $\mathrm{V}$ is VP, not $\mathrm{S}$ (which is presumably IP, the maximal projection of the category I, or Infl). The essential grammatical information in a verbal lexical entry consists of its syntactic projection and its LCS, together with a registration of the lexical TRA (theta-roleassignment) relation(s) holding between the two. A lexical TRA can be understood as involving the projection of a variable from LCS onto an argument position in the LS syntactic projection. English cut, being transitive, has an internal argument. As with transitive "verbs of affecting" generally, the "passive» participant (corresponding to the $y$-variable in (4)) is associated with the object function. Thus, the lexical TRA will relate the $y$-variable with the internal argument position, as depicted in the following grammatical entry for cut, in which the LCS is abbreviated and in which only the LS aspect of the syntactic projection is given (using lower case categorial labels to distinguish LS from PS): 
(5)

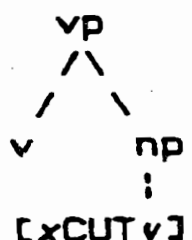

The notion «external Theta-Role» derives immediately from the fact that the verb, in English (and a great many other languagues, of course), is lexically autonomous from Infl. Thus, for example, the "agent» role of cut (corresponding to the $x$-variable) cannot be associated with an argument position in the lexical entry. The subject grammatical function, to which the external thetarole is assigned (via predication), becomes available when the verb enters into a syntactic construction with Infl, as in the structure (6), corresponding to sentence (1):

(6)

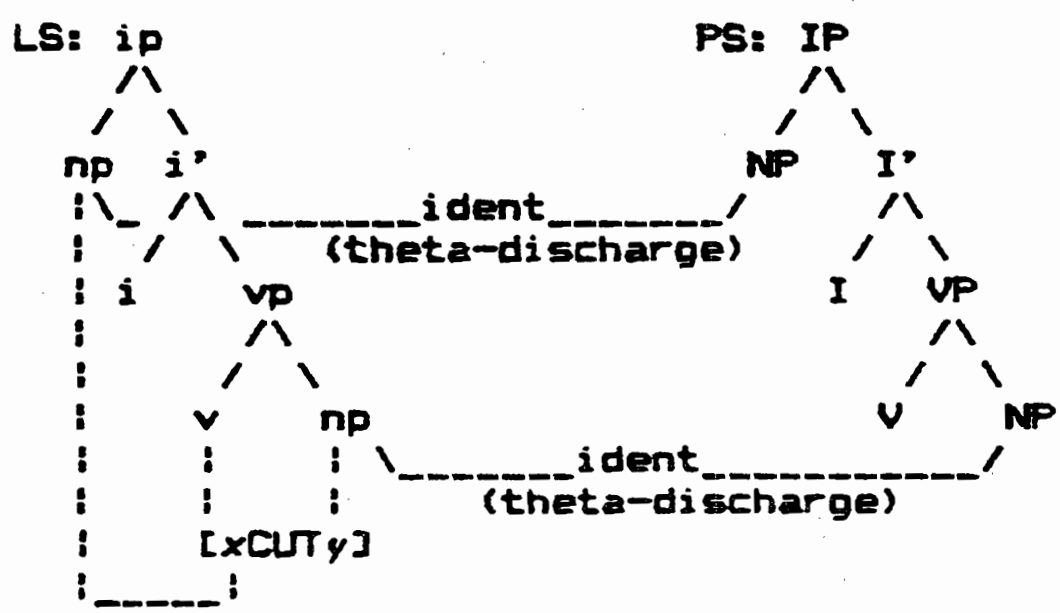

One fate of the "external argument» in English is illustrated here; it is assigned, via predication, to the argument appearing in the specifier of Infl, i.e., to the canonical «subject» position. Sentence (2) illustrates another possibility; there, the external thetarole of cut is assigned, again via predication, to the object of the main verb. Finally, in (3), an example of the so-called middle construction, the external theta-role of cut is not assigned to an argument position at all, since NP-movement has filled the position to which it would otherwise have been assigned via predication (cf. Hale and Keyser, 1985). 
In (6), both the LS and the PS aspects of the syntactic projection are presented. The relation between these representations, in English, and in configurational constructions generally, is essentially one of identity, except for the fact that left-right linear order of constituents is relevant only at PS, where language-particular directionality principles are expressed.

The defining characteristic of "configurational" constructions, as I will use the term here, lies in the nature of the relationship between argument positions in the LS and PS representations. And this, in turn, relates to the process of theta-role discharge, or theta-role saturation, which is fundamental to the Projection Principle (cf. Chomsky, 1981; Rizzi, 1985). A theta-role associated with an argument position in LS in properly "discharged», or "saturated", only if the argument position is properly identified, in the sense of having "content» (e.g., as a pronominal, bound anaphor, or referential expression). In configurational constructions, the required identification of an LS argument position is effected by the identity relation which holds between the LS position and a corresponding category in PS, as depicted in (6) above. A configurational construction, therefore, requires that arguments be present at PS in order to satisfy the Projection Principle.

In a nonconfigurational construction, by contrast, the identification of LS argument positions, and therefore, the proper discharge of theta-roles, is effected "internally», so to speak. Consider, for example, the following Navajo sentences:

(7) Ashkii at'ééd yiyiił tsą́. [SUBJ OBJ yi-VERB]

(boy girl 3-3-saw)

'The boy saw the girl'.

(8) At'ééd yiyiiłtsą́. [OBJ yi-VERB]

(girl 3-3-saw)

'He/she saw the girl'.

(9) Yiyii $\nmid$ tsą́

(3-3-saw)

'He/she saw him/her'.

In sentences of this sort, the presence of an overt nominal expression, corresponding to the subject or object grammatical function, is not required. Thus, sentences (8) and (9) are just as "complete" as (7), in which the subject and object are overtly represented by NPs. This is, of course, a familiar situation, and is typically taken to be a manifestation of the pro-drop option, available to some languages by virtue of a parameter of universal grammar (cf. Chomsky, 1981; Rizzi, 1985; and elsewhere). My interpretation of this option for Navajo, and languages of the type it represents, is as follows. Argument positions in LS are fully identified (as pronominals or anaphors, depending on the verbal 
inflection) and, therefore, suffice to discharge the theta roles associated with the verb, as required by the Projection Principle. Hence, the latter does not motivate the appearance of NP expressions at PS. Furthermore, for this very reason, an overt NP expression in PS need not bear the identity relation to an argument position in LS. This fact is essential to an understanding of the "nonconfigurational» nature of languages like Navajo. Overt NPs are not themselves arguments (cf. Jelinek, 1984, and Saito, 1985, where this view of the matter is also advanced). Rather, I would like to suggest, overt NPs in Navajo are related to LS argument positions by resumption, as depicted in (10), the structure corresponding to (7) above:

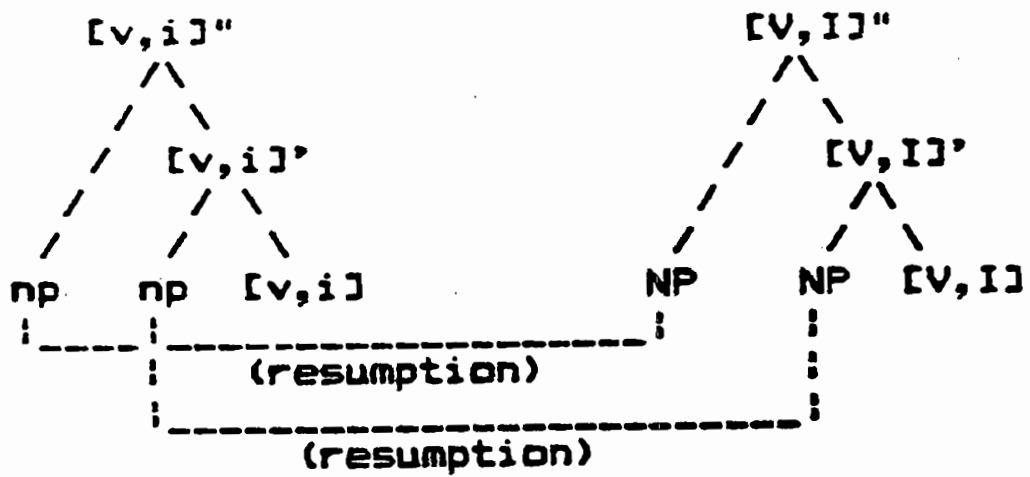

At LS, the arguments are identified as pronominals (in this case, third person, definite, as indicated in the verbal inflection), and they function, according to the view I am adopting, as resump. tive pronouns in relation to the overt nominal expressions in PS. (Navajo, unlike English, projects Infl and $\mathrm{V}$ as a single unit in syntax; grammatical relations, at LS, are the same for both languages, however, so that «subject» is specifier of Infl, and «object» is a complement of the verb).

The special relation between LS arguments and overt nominals in PS is revealed by sentences like (11) below, discussed briefly in Platero (1982):

(11) Adąąádąąá ashkii at'ééd yiyiiłtsán-ęę yidoots'os. (yesterday boy girl 3-3-saw-REL 3-3-will-kiss) 'The boy will kiss the girl he saw yesterday'. ' $\mathrm{He} / \mathrm{she}<\mathrm{i}>$ will kiss the girl that the boy $<\mathrm{j}>$ saw yesterday'.

The substring adq̣ád q́ă' ashkii at'ééd yiyiił tsán-ęé ('the girl whom the boy saw yestesday') is a complex NP corresponding to the 
object grammatical function in relation to the main verb yidoots'os ('he will kiss her'). It is a much-studied fact of Navajo (see, e.g., Platero, 1982, and references cited there) that the GF associations of an overt NP can be determined from surface structure, on the basis of linear order and verbal morphology. For our purposes, it is sufficient to note that an NP immediately preceding a verb containing the third person object prefix $y i$ - is associated with the object function; the subject, if present, must precede the NP adjacent to the verb. That is to say, the string schema [(NP) NP yi-V] is interpreted as [(SUB) OBJ V]. Sentence (11), interpreted as indicated in the first translation, shows that the PS representation in Navajo cannot have an NP (say the category pro) in subject position, i.e., preceding the overt complex NP object of the main verb. If an NP subject were present in PS, it would bind the R-expression ashkii ('the boy'), appearing internal to the object of the main verb, giving rise to a violation of condition $\mathrm{C}$ of the Binding Theory (according to which an R-expression must be free; Chomsky, 1981). The possibility that there is no NP in subject position at PS is, of course, allowed in Navajo, assuming that the appearance of overt NPs is not motivated by the Projection Principle in that language. Sentence (11) also shows that an overt NP in Navajo may bear the resumptive relation (rather than the identity relation) to an LS argument position. Again, condition $\mathrm{C}$ is the relevant principle; if the complex NP bore the identity relation to the object position in the LS of (11), the subject (a pronominal) would bind the R-expression ashkii, internal to the object, violating condition $\mathrm{C}$.

In conclusion, I suspect strongly that there is no single "parameter» giving rise to the various properties commonly associated with the term «nonconfigurational». I have used the term here to refer to a particular relation holding between the LS and PS aspects of the syntactic projections of lexical items. There are actually two "parameters» involved here: (1) the pro-drop parameter, whose setting determines whether or not an LS argument position is fully identified in the LS representation itself (perhaps by virtue of "rich inflection", as in Navajo, though it remains to be seen to what extent this is actually required in languages generally); and (2) the resumption parameter, whose setting determines whether or not an overt expression in PS is required to bear the identity relation to an argument position in LS. With regard to the first of these parameters, Navajo is evidently a pro-drop language. And with regard to the second, sentences of the type represented by (11) suggest that it is also a language in which 
overt NP expressions bear the resumptive relation to LS argument positions. Basque, by contrast, while crearly a pro-drop language, differs from Navajo in that it requires overt NP expressions to bear the identity relation with LS argument positions. Sentences constructed on the model of (11) are ungrammatical in Basque. The same is true of Korean and Japanese, whatever their status in relation to the pro-drop parameter might ultimately prove to be.

\section{REFERENCES}

CHOMSKY, N. (1981) Lectures on Government and Binding, Dordrecht: Foris Publications.

HALE, K. (1983) «Warlpiri and the Grammar of Non-configurational Languages»; Natural Language \& Linguistic Theory, 1, 5-47.

Unpublished Manuscript, M.I.T., Cambridge, Massachusetts [to appear in Anuario del Seminario de Filología Vasca "Julio de Urquijo» XX-3 (1986)].

JELINEK, E. (1984) «Empty Categories, Case, and Configurationality», Natural Language \& Linguistic Theory, 2, 39-76.

MOHANAN, K. P. (1983/4) "Lexical and Configurational Structures», The Linguistic Review, 3, 113-139.

PLATERO, P. (1982) «Missing Noun Phrases and Grammatical Relations in Navajo», International Journal of American Linguistics, 48, 286-305.

RIZZI, L. (1985) "Null Objects in Italian and the Theory of pro», Unpublished Manuscript, M.I.T., Cambridge, Massachusetts.

SAITO, M. (1985) Some Asymmetries in Japanese and their Theoretical Implications, M.I.T. Doctoral Dissertation, Cambridge, Massachusetts.

WHITMAN, J. (1982) «Configurationality Parameters», Unpublished Manuscript, Harvard University, Cambridge, Massachusetts. 